\title{
Article \\ Double-Stranded RNA Enhances Matrix Metalloproteinase-1 and -13 Expressions through TLR3-Dependent Activation of Transglutaminase 2 in Dermal Fibroblasts
}

\author{
Ah-Young Hong ${ }^{1,+}$, Seok-Jin Lee ${ }^{1,+}$, Ki Baek Lee ${ }^{1,2,+} \mathbb{D}$, Ji-Woong Shin ${ }^{1} \mathbb{D}$, Eui Man Jeong ${ }^{3}(\mathbb{D}$ \\ and In-Gyu Kim 1,2,4,*
}

Citation: Hong, A.-Y.; Lee, S.-J.; Lee, K.B.; Shin, J.-W.; Jeong, E.M.; Kim,

I.-G. Double-Stranded RNA

Enhances Matrix Metalloproteinase-1 and -13 Expressions through TLR3-Dependent Activation of Transglutaminase 2 in Dermal Fibroblasts. Int. J. Mol. Sci. 2022, 23, 2709. https://doi.org/10.3390/ ijms23052709

Academic Editors: Simone Beninati and Carlo Mischiati

Received: 24 January 2022

Accepted: 25 February 2022

Published: 28 February 2022

Publisher's Note: MDPI stays neutral with regard to jurisdictional claims in published maps and institutional affiliations.

Copyright: (c) 2022 by the authors. Licensee MDPI, Basel, Switzerland. This article is an open access article distributed under the terms and conditions of the Creative Commons Attribution (CC BY) license (https:// creativecommons.org/licenses/by/ $4.0 /)$.
1 Department of Biochemistry and Molecular Biology, Seoul National University College of Medicine, Seoul 03080, Korea; ay630@naver.com (A.-Y.H.); ylsj111@naver.com (S.-J.L.); lkb3431@snu.ac.kr (K.B.L.); earthbear3@gmail.com (J.-W.S.)

2 Laboratory for Cellular Response to Oxidative Stress, Cell2in, Inc., Seoul 03127, Korea

3 Department of Pharmacy, College of Pharmacy, Jeju National University, Jeju 63243, Korea; euimanjeong@gmail.com

4 Department of Human-Environment Interface Biology, Seoul National University College of Medicine, Seoul 03080, Korea

* Correspondence: igkim@snu.ac.kr

+ These authors contributed equally to this work.

\begin{abstract}
UV-irradiation induces the secretion of double-stranded RNA (dsRNA) derived from damaged noncoding RNAs in keratinocytes, which enhance the expression of matrix metalloproteinases (MMP) in non-irradiated dermal fibroblasts, leading to dysregulation of extracellular matrix homeostasis. However, the signaling pathway responsible for dsRNA-induced MMP expression has not been fully understood. Transglutaminase 2 (TG2) is an enzyme that modifies substrate proteins by incorporating polyamine or crosslinking of proteins, thereby regulating their functions. In this study, we showed that TG2 mediates dsRNA-induced MMP-1 expression through NF-kB activation. Treatment of poly(I:C), a synthetic dsRNA analogue binding to toll-like receptor 3 (TLR3), generates ROS, which in turn activates TG2 in dermal fibroblast. Subsequently, TG2 activity enhances translocation of p65 into the nucleus, where it augments transcription of MMP. We confirmed these results by assessing the level of MMP expression in Tlr3-/-, TG2-knockdowned and Tgm $2^{-/-}$dermal fibroblasts after poly(I:C)-treatment. Moreover, treatment with quercetin showed dose-dependent suppression of poly(I:C)-induced MMP expression. Furthermore, ex vivo cultured skin from $T g m 2^{-/-}$mice exhibited a significantly reduced level of MMP mRNA compared with those from wild-type mice. Our results indicate that TG2 is a critical regulator in dsRNA-induced MMP expression, providing a new target and molecular basis for antioxidant therapy in preventing collagen degradation.
\end{abstract}

Keywords: transglutaminase 2; double-stranded RNA (dsRNA); matrix metalloproteinases (MMP); dermal fibroblasts; poly(I:C); ROS

\section{Introduction}

Skin wrinkling is a prominent feature of aged skin and thought to be caused by an increase of reactive oxygen species (ROS) production due to mitochondrial dysfunction of senescent dermal fibroblast [1]. Oxidative stress induces upregulation of matrix metalloproteinase-1 (MMP-1), an enzyme responsible for degradation of type I collagen, a major component of dermal extracellular matrix (ECM). Moreover, oxidative stress also reduces the synthesis of type I collagen in dermal fibroblasts leading to dysregulation of ECM homeostasis and decreased dermal thickness [2]. In sun-exposed skin, UV irradiation is known to induce ROS generation such as singlet oxygen $\left({ }^{1} \mathrm{O}_{2}\right)$, superoxide anion $\left(\mathrm{O}_{2}{ }^{-}\right)$, hydrogen peroxide $\left(\mathrm{H}_{2} \mathrm{O}_{2}\right)$, and hydroxyl radicals $(\mathrm{OH} \cdot)$, and thus aggravates the dysregulation of ECM remodeling through MMP-1 expression, resulting in premature skin 
aging [3]. However, the signaling pathway involved in the regulation of MMP-1 expression in UV-irradiated or oxidatively stressed dermal fibroblasts has not been fully understood.

Double stranded RNAs (dsRNA) are generated in virus-infected cells during its replication, and play a role in eliciting anti-viral responses by binding toll-like receptor 3 (TLR3), a member of the pattern recognition receptor family, and retinoic acid-inducible gene I (RIG-I)-like receptors (RLRs) [4]. TLR3 and RLRs then activate various signaling pathways, such as NF-kB, and MAPK signaling, leading to production of proinflammatory cytokines and induction of interferon-stimulated genes through transcriptional regulation [5]. Interestingly, dsRNA is also produced in stressed, apoptotic or necrotic cells. A previous report showed that UV-irradiation damages noncoding RNAs in keratinocytes, producing and releasing dsRNA, which triggers non-irradiated cells to induce the expression of TLR3-dependent inflammatory cytokines, such as TNF- $\alpha$ and IL-6, thereby eliciting skin inflammatory reactions [6]. Moreover, poly(I:C) induces MMPs' expression in human dermal fibroblasts [7]. These findings indicate that dsRNA functions as a signaling molecule to induce skin responses in response to genotoxic stresses in addition to viral infection.

Transglutaminase 2 (TG2) is a member of the enzyme family that modifies substrate proteins by catalyzing polyamine incorporating or $\varepsilon$ ( $\gamma$-glutamyl) lysine protein crosslinking reactions [8]. These modifications affect the activity of substrate proteins by altering protein-protein interaction or their solubility $[9,10]$. TG2 is unique among TG isoenzymes in that intracellular TG2 is activated in response to various stresses, such as UV-irradiation or treatment with DNA-damaging chemotherapeutics, otherwise held in latent inactive enzyme [11,12]. UV-irradiation activates TG2 by one of two mechanisms: (i) by releasing endoplasmic reticulum (ER) calcium [13]; (ii) by activating TGF $\beta$ signaling pathway [11] or possibly redox signaling pathway, depending on the level of oxidative stress. Moreover, TG2 is not activated when treated with actinomycin D after oxidative stress, suggesting that TG2 is activated by TGF $\beta$ or redox signaling-mediated regulation of gene expression. In the skin, UV-irradiation activates intracellular TG2 in epidermal keratinocytes which enhances NF-kB transcriptional activity and production of proinflammatory cytokines, leading to acute inflammation [13]. Recently, we have shown that TG2 mediates UV-induced MMP-1 expression through NF-kB activation in dermal fibroblasts [14]. Thus, TG2 is a critical regulator in UV-induced skin inflammation and ECM remodeling.

UV-irradiation elicits skin inflammation and ECM remodeling through activation of various signaling pathways, where both dsRNA and TG2 participate as a mediator, respectively. In this study, we have investigated the possibility that dsRNA regulates TG2 in the UV-induced MMP expression in dermal fibroblasts, and showed that dsRNA activates TG2 through TLR3-dependent ROS production, resulting in enhancement of NF-kB signaling and subsequent MMP-1 and -13 expression. Our results identify dsRNA-TLR3TG2-NF-kB as an effector pathway responsible for ECM remodeling in UV-exposed skin, providing new targets to prevent skin wrinkling.

\section{Results}

\subsection{Poly(I:C) Enhances MMP-1 and -13 Expression through TG2 Activation}

To test whether TG2 is involved in the regulation of dsRNA-induced MMP expression, we examined the effect of TG2 knock-down on the levels of MMP expression. In human dermal fibroblasts (HDFs), treatment with poly(I:C), a synthetic dsRNA analog, caused a time-dependent increase in the levels of MMP1 and 13 mRNA up to $24 \mathrm{~h}$ (Figure 1A). In TG2 knock-downed HDFs, levels of MMP1 and 13 mRNA were significantly reduced in response to poly $(\mathrm{I}: \mathrm{C})$ treatment compared with those of control siRNA-treated cells (Figure 1B). Moreover, Western blot analysis showed that TG2 knock-down reduces the level of poly(I:C)-induced MMP-1 protein compared with that of control cells. Notably, poly(I:C) treatment upregulated the protein level of TG2 (Figure 1C). To corroborate these results, we compared collagenase activity of MMPs in both cells using DQ-collagen type 1 as a substrate [15]. Poly(I:C) treatment significantly increased the intensity of DQ-fluorescence in control siRNA-treated cells compared with saline-treated cells, but had no effect in 
TG2 knock-downed cells (Figure 1D). Furthermore, treatment with cysteamine, which is a non-specific inhibitor, though TG2 is the only isoform expressed in dermal fibroblasts, reduces the level of poly(I:C)-induced $M M P 1$ and 13 mRNA (Figure 1E). These results indicate that TG2 mediates poly(I:C)-induced MMP expression.

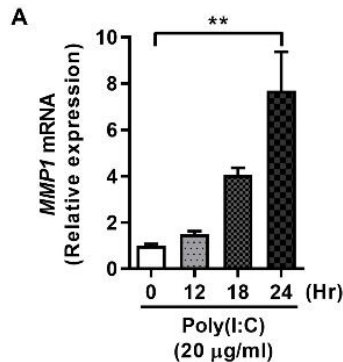

C

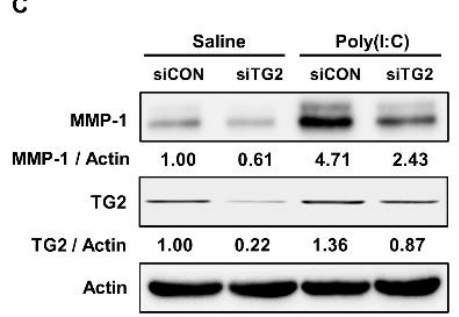

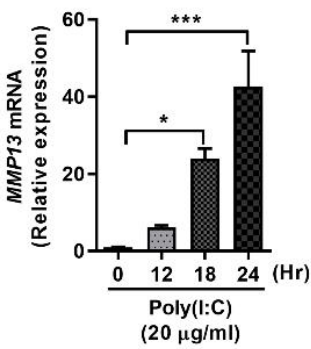

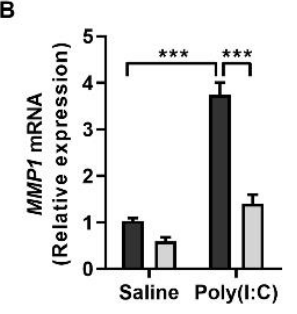

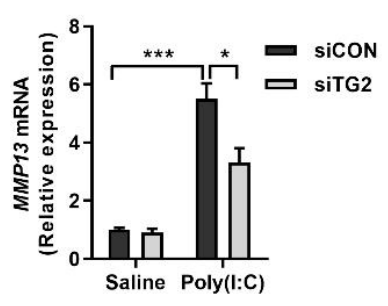

D

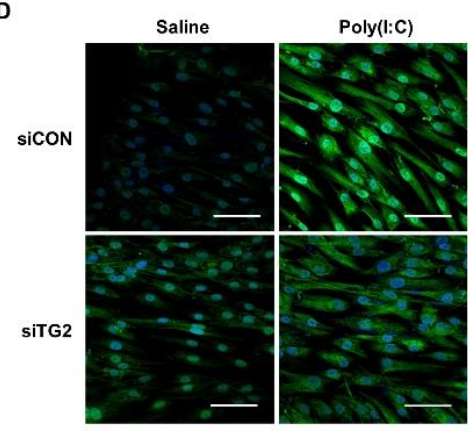

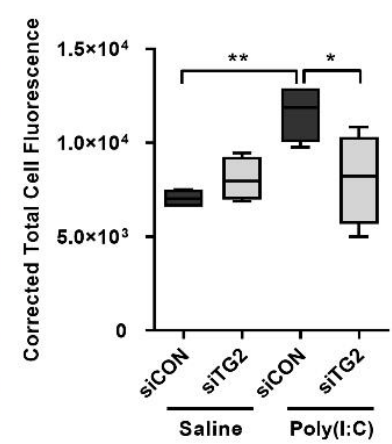

E
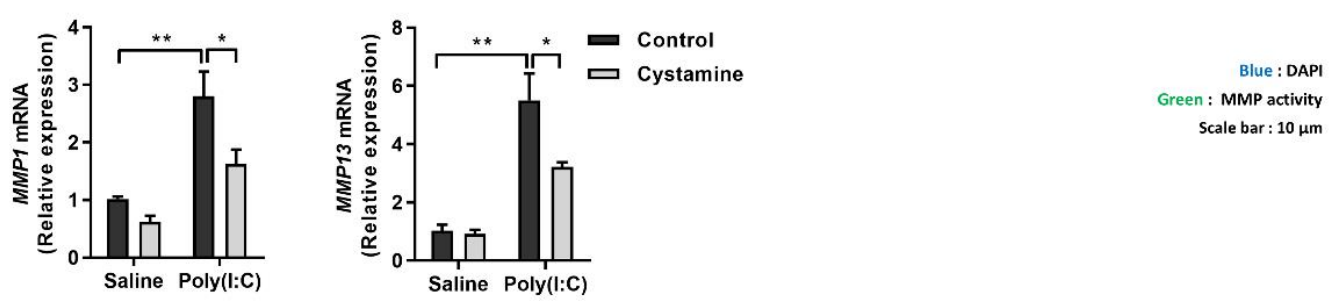

Figure 1. Poly(I:C) enhances MMP-1 and -13 expression through TG2 activation in HDFs. (A) HDFs were treated with $20 \mu \mathrm{g} / \mathrm{mL}$ of poly(I:C), and mRNA levels of MMP1 and MMP13 were monitored for $24 \mathrm{~h}$ using qRT-PCR. $(n=3)(\mathbf{B}, \mathbf{C})$ TG2 expression of HDFs was knock-downed with siRNA. Cells were then treated with $20 \mu \mathrm{g} / \mathrm{mL}$ of poly(I:C) for $24 \mathrm{~h}$. Levels of MMP1 and MMP13 mRNA (B) and MMP-1 protein (C) were measured using qRT-PCR and Western blotting, respectively. $(n=3)$ (D) TG2-knockdowned HDFs were treated with $20 \mu \mathrm{g} / \mathrm{mL}$ poly(I:C) for $24 \mathrm{~h}$ and then were incubated with $10 \mu \mathrm{g} / \mathrm{mL} \mathrm{DQ}^{\mathrm{TM}}$-collagen I for $1 \mathrm{~h}$. Intracellular MMPs activity was visualized using confocal microscope (left, scale bar: $10 \mu \mathrm{m}$ ) and quantitated by measuring corrected total cell fluorescence using Image J (right, $n=11$ ). (E) HDFs were pretreated with cysteamine (100 $\mu \mathrm{M}$ for $1 \mathrm{~h}$ ) before poly(I:C) treatment $(20 \mu \mathrm{g} / \mathrm{mL}$ for $2 \mathrm{~h}$ ). Levels of $M M P 1$ and MMP13 mRNA were measured using qRT-PCR. $(n=3)$ All data are represented as mean \pm SEM. Statistical significance was tested by one-way ANOVA by Dunnett's post-test (A) or two-way ANOVA by Turkey's post-test (B,D,E). ${ }^{*}, p<0.05 ;{ }^{* *}, p<0.01 ;{ }^{* *}, p<0.001$.

To confirm these results, we compared the ability of wild-type and $\operatorname{Tgm}^{-/-}$mouse dermal fibroblasts (MDFs) to promote Mmp13 expression in response to poly(I:C) treatment. In MDFs prepared from wild-type mice, poly(I:C) treatment resulted in a dose and time-dependent increase of Mmp13 mRNA peaked at $20 \mu \mathrm{g} / \mathrm{mL}$ and after $12 \mathrm{~h}$, respectively (Figure 2A). Under these experimental conditions, by contrast, Tgm2-/- MDFs showed significantly reduced level of and Mmp13 mRNA and protein compared with wild-type MDFs (Figure 2B). These results were verified by measuring collagenase activity. Poly(I:C) 
treatment induced a significant increase of collagenase activity in wild-type MDFs compared with saline-treated cells, but had no effect on that of $\mathrm{Tgm}^{-/-}$MDFs (Figure 2C). Intracellular TG2 is known to be inactive under physiological culture conditions [11]. We then established the causal relationship between $\mathrm{Tg} 2$ and Mmp13 expression by monitoring Tg2 activity after poly(I:C) treatment. MDFs were exposed to poly(I:C) and then incubated with biotinylated pentylamine (BP). After cell lysis, BP-incorporated proteins were estimated by streptavidin-HRP. Wild-type MDFs showed a gradual increase in the levels of TG activity which peaked at $9 \mathrm{~h}$, but $\mathrm{Tgm}^{-/-}$cells exhibited basal levels of enzyme activity (Figure 2D). Furthermore, $\mathrm{Tg} 2$ protein level parallel to the TG activity was gradually increased by poly(I:C) treatment, but is not well-correlated with in situ TG activity. Visualization of intracellular BP-incorporated proteins further confirmed poly(I:C)-induced Tg2 activation (Figure 2E). Together, our results indicate that poly(I:C) upregulates and activates TG2, thereby promoting MMP expression.

A
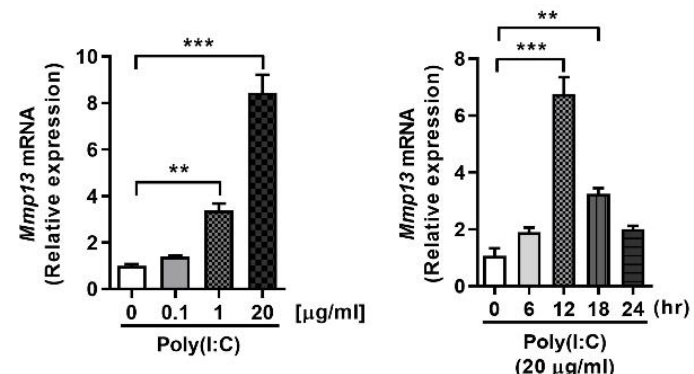

C

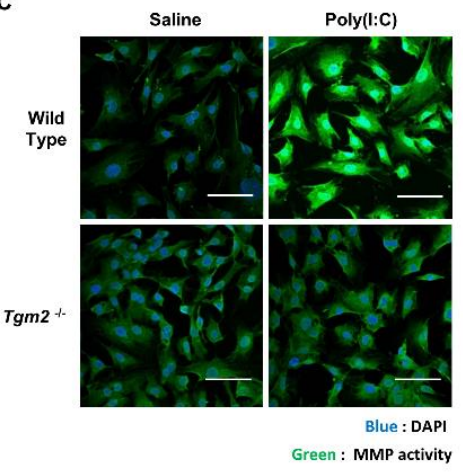

D
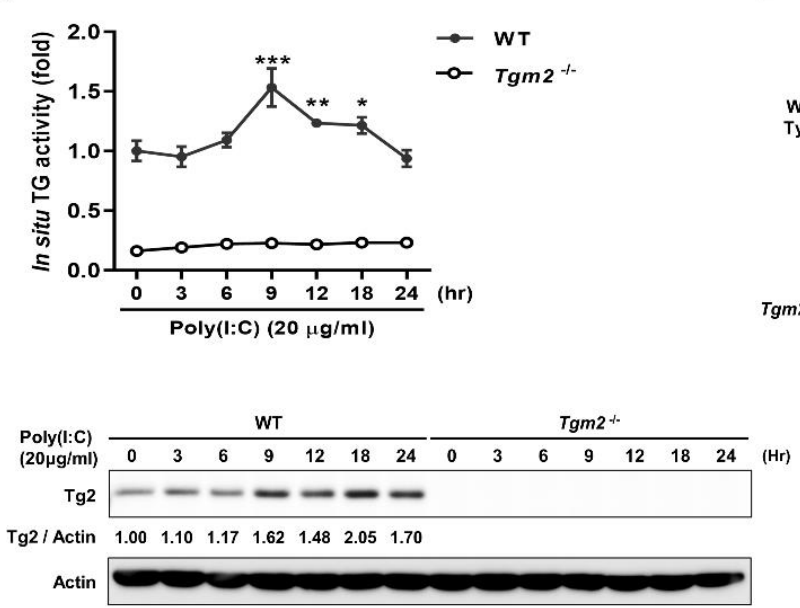

B
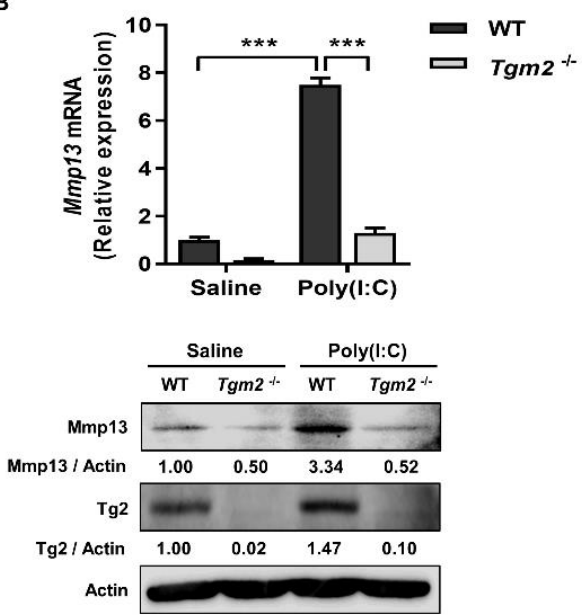

E

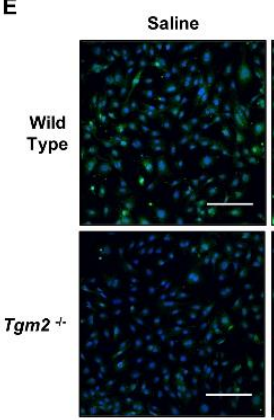

Poly(l:C)

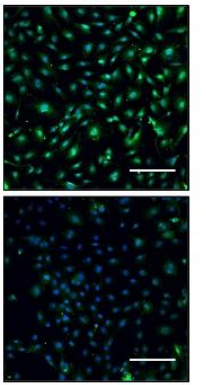

Blue : DAPI

Green : Tg activity

Scale bar : $10 \mu \mathrm{m}$

Figure 2. Tgm2-deficient MDFs exhibit reduced Mmp-13 expression in response to poly(I:C) treatment. (A) MDFs were treated with various concentrations of poly(I:C), and mRNA levels of Mmp13 were 
measured after $12 \mathrm{~h}$ using qRT-PCR (left, $n=3$ ). Mmp13 mRNA levels of MDFs treated with $20 \mu \mathrm{g} / \mathrm{mL}$ of poly(I:C) were monitored for $24 \mathrm{~h}$ (right, $n=3$ ). (B) Mmp13 mRNA level (upper panel) and Mmp13 protein (lower panel) of wild-type and $T g m 2^{-/-}$MDFs were measured using qRT-PCR and western blotting, respectively, after treatment with $20 \mu \mathrm{g} / \mathrm{mL}$ of poly(I:C) for $12 \mathrm{~h}$. $(n=3)(\mathrm{C})$ Intracellular MMPs activity of wild-type and Tgm2-/- MDFs was visualized after treatment with $20 \mu \mathrm{g} / \mathrm{mL}$ of poly(I:C) for $12 \mathrm{~h}$ using $\mathrm{DQ}^{\mathrm{TM}}$-collagen I (left) and quantitated by measuring corrected total cell fluorescence using Image J (right, $n=11$ ). (D) Wild-type and Tgm2 ${ }^{-/-}$MDFs were treated with poly(I:C) $(20 \mu \mathrm{g} / \mathrm{mL}$ for $12 \mathrm{~h})$. Intracellular TG activity (upper panel) and Tg2 protein level (lower panel) were monitored for $24 \mathrm{~h}$ using biotinylated pentylamine (BP) incorporation assay $(n=3)$ and western blotting. Intracellular TG activity was visualized by detection of BP incorporated proteins using Streptavidin-FITC (E). All data are represented as mean \pm SEM. Statistical significance was tested by one-way ANOVA by Dunnett's post-test (A) or two-way ANOVA by Turkey's post-test (B-D). ${ }^{*}, p<0.05 ;{ }^{* *}, p<0.01 ;{ }^{* * *}, p<0.001$.

\subsection{ROS Generated by Binding of Poly(I:C) with TLR3 Activates TG2}

dsRNA is recognized by TLR3 that transduces signals to IRF3 and NF- $\kappa$ B by recruiting the TIR domain-containing adaptor molecule 1 (TICAM1), leading to induction of type 1 interferon and inflammatory cytokines [16]. To test whether Tlr3 is implicated in the poly(I:C)-induced TG2 activation, we treated wild-type and Tlr3 ${ }^{-/}$MDFs with poly(I:C) and measured intracellular TG activity. Poly(I:C) treatment caused a significant increase of TG activity of wild-type cells but not that of $T / r 3^{-/-}$cells compared with saline-treated cells (Figure 3A), indicating that Tlr3 is required for poly(I:C)-induced TG2 activation. In WT and Tlr3 ${ }^{-/-}$MDFs, poly(I:C) treatment had no effect on the level of Tg2 mRNA and protein compared with saline-treated cells (Figure 3B,C). By contrast, poly(I:C) treatment increased the level of Tlr3 mRNA (Figure 3D), suggesting that the expression of Tg2 and Tlr3 may be regulated by negative and positive feedback mechanisms, respectively, in poly(I:C)-treated MDFs.
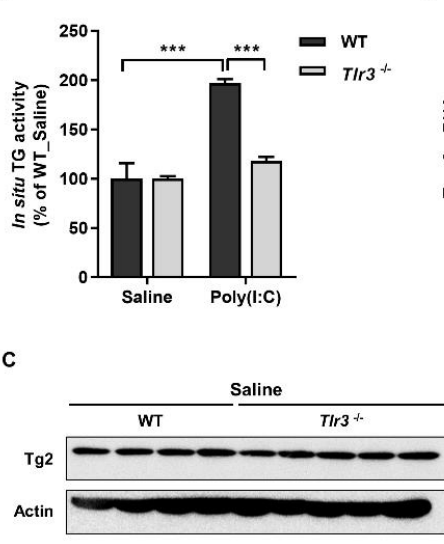

D

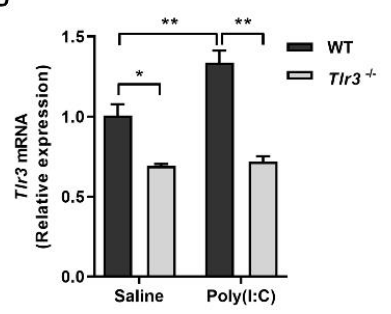

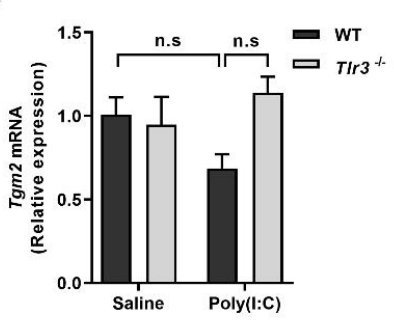
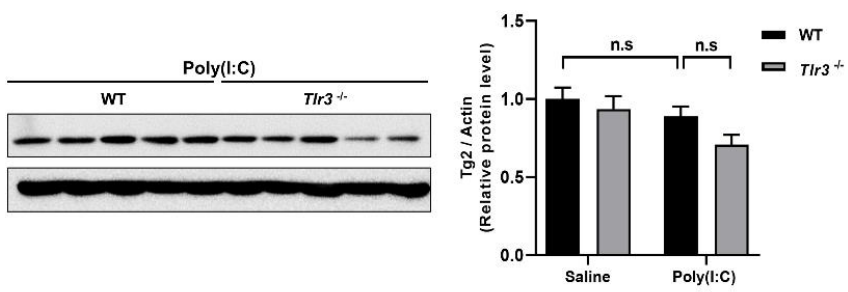

Figure 3. Tlr3 is required for poly(I:C)-induced Tg2 activation in MDFs. (A-D) Wild-type and Tlr3-/MDFs were treated with $20 \mu \mathrm{g} / \mathrm{mL}$ of poly(I:C) for $9 \mathrm{~h}$. Intracellular TG activity was measured using 
biotinylated pentylamine (BP) incorporation assay $((\mathbf{A}), n=3)$. mRNA level of Tgm2 and protein level of Tg2 were measured using qRT-PCR $((\mathbf{B}), n=3)$ and western blotting $(\mathbf{C})$, respectively. The ratio of Tg2 to Actin was estimated by densitometric analysis of Western blot (C, right). mRNA level of Tlr3 were measured using qRT-PCR (D). All data are represented as mean \pm SEM. Statistical significance was tested by two-way ANOVA by Turkey's post-test. ${ }^{*}, p<0.05 ;{ }^{* *}, p<0.01$; ${ }^{* * *}, p<0.001$; n.s., not significant.

We next investigated the mechanism through which binding of poly(I:C) with TLR3 may affect TG2 activity. It has been reported that activation of TLR3 induces ROS generation by recruiting NOX2 in macrophage [17]. To test whether poly(I:C) generates ROS through TLR3 binding, we compared ROS levels after poly(I:C) treatment in wild-type and $T l r 3^{-/-}$MDFs by measuring oxidation of redox-sensitive fluorescent dye $\mathrm{H}_{2}$ DCFDA. Flow cytometric analysis showed that control Tlr $3^{-/-}$MDFs exhibit significant low ROS levels compared with control wild-type MDFs. Poly(I:C) treatment had increased the ROS level gradually in both MDFs, but the ROS level in $\mathrm{Tlr}^{-/-} \mathrm{MDFs}$ still remained lower than that of wild-type MDFs (Figure 4A). These results suggest that poly(I:C) treatment generates ROS by binding to TLR3 and by unknown mechanism. Under the same experimental conditions, in contrast, there was no significant difference in fluorescence intensity between wild-type and $\mathrm{Tgm} 2^{-/-}$MDFs (Figure $4 \mathrm{~B}$ ), indicating that poly(I:C) generates ROS by binding with TLR3.

A

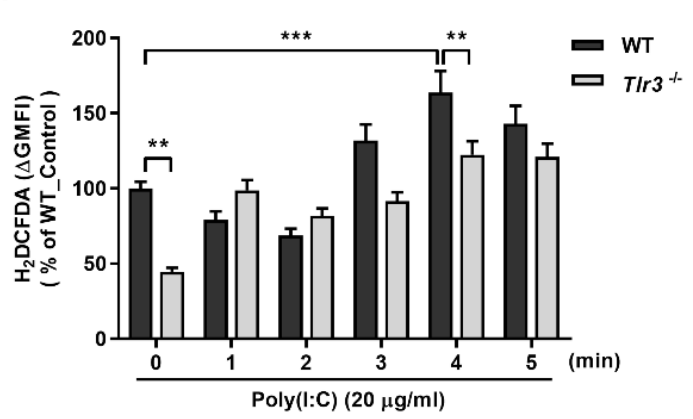

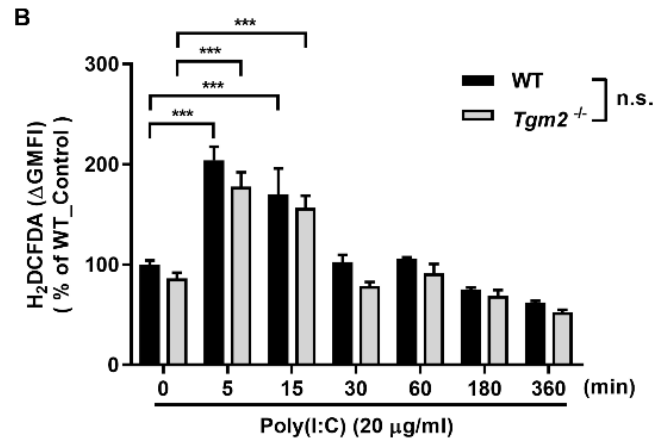

D
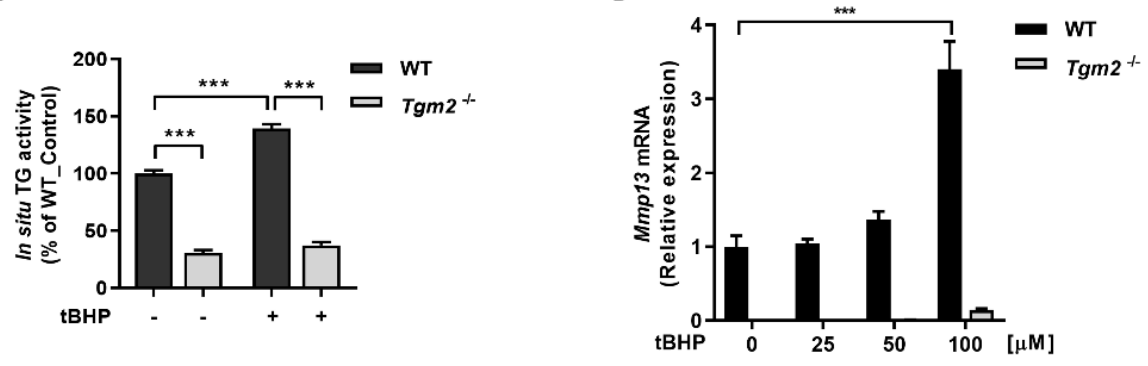

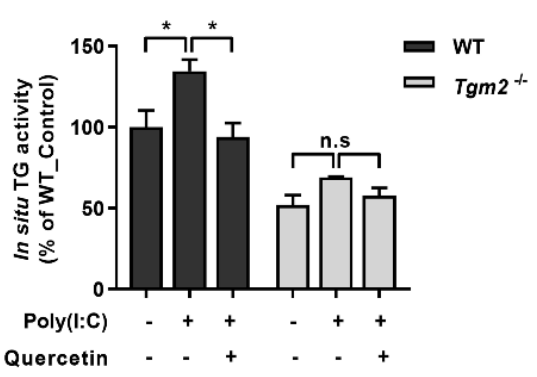

F

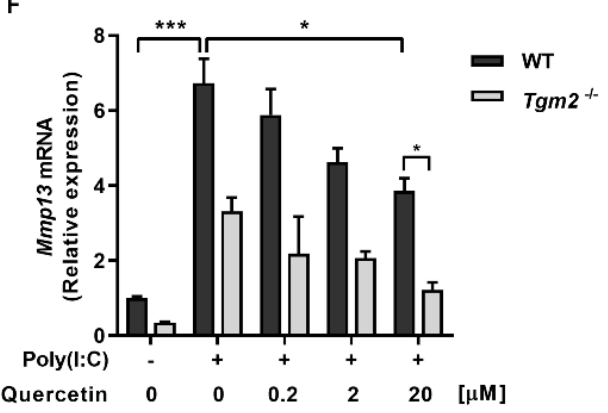

Figure 4. Poly(I:C) binding to TLR3 generates ROS that activates TG2. (A,B) Wild-type and Tlr3 ${ }^{-/-}$ (A) or $T g m 2^{-/-}$(B) MDFs were treated with $20 \mu \mathrm{g} / \mathrm{mL}$ of poly(I:C) and harvested at indicated time. 
Levels of ROS in the cells were quantitatively measured by flow cytometry using DCFDA. (C,D) Wildtype and $T g m 2^{-/-}$MDFs were treated with $100 \mu \mathrm{M}(\mathrm{C})$ or various dose (D) of tert-butyl hydroperoxide (tBHP) for $12 \mathrm{~h}$. The levels of intracellular TG activity $(\mathbf{C}, n=3)$ and Mmp13 mRNA ((D), $n=3$ ) were evaluated by BP incorporation assay and by qRT-PCR, respectively. (E,F) Wild-type and $\mathrm{Tgm}^{-1-}$ MDFs were treated with $20 \mu \mathrm{g} / \mathrm{mL}$ of poly(I:C) for $12 \mathrm{~h}$. Effect of co-treatment with $20 \mu \mathrm{M}$ (E) or various dose $(\mathbf{F})$ of quercetin for $9 \mathrm{~h}$ on the levels of intracellular Tg activity $((\mathbf{E}), n=3)$ and Mmp13 mRNA ((F), $n=3)$ was evaluated by BP incorporation assay and by qRT-PCR, respectively. All data are represented as mean \pm SEM. Statistical significance was tested by two-way ANOVA by Turkey's post-test. ${ }^{*}, p<0.05 ;{ }^{* *}, p<0.01 ;{ }^{* * *}, p<0.001$; n.s., not significant.

To test whether poly(I:C)-generated ROS activates TG2, we firstly assessed the effect of tert-butyl hydroperoxide (tBHP) treatment on TG activity. Treatment with $\mathrm{tBHP}$ resulted in a significant increase of intracellular TG activity in wild-type MDFs, but not in $\mathrm{Tgm}^{-{ }^{-/-}}$ cells (Figure 4C). When cells were treated with poly(I:C), a similar increase of TG activity was observed in wild-type MDFs. In contrast, co-treatment with quercetin decreased TG activity to the baseline levels. Both poly(I:C) or quercetin treatment showed no effect on TG activity in $T g m 2^{-/-}$cells (Figure 4E). Under these conditions, we also examined the effect $\mathrm{tBHP}$ and poly(I:C) on MMP-13 expression. Treatment with $\mathrm{tBHP}$ induced a dosedependent increase of Mmp13 mRNA in wild-type MDFs, but it had no effect on the levels of Mmp13 expression in Tgm2-/- cells (Figure 4D). Similarly, poly(I:C) treatment increased the level of Mmp13 mRNA in wild-type MDFs, whereas co-treatment with quercetin decreased the level of poly(I:C)-induced Mmp13 expression in a quercetin dose-dependent manner. The effect of quercetin co-treatment was not observed in $\mathrm{Tgm}^{-/-}$cells (Figure 4F). Thus, our results indicate that poly(I:C)-induced ROS upregulate Mmp13 expression by activating TG2 in MDFs.

\subsection{TG2 Mediates Poly(I:C)-Induced NF-kB Activation}

Expression of MMPs is known to be regulated by NF- $\mathrm{kB}$ and AP-1 transcription factor [18], and dsRNA induces activation of NF-kB, JNK and p38 through TLR3 [19]. To determine which signaling pathway(s) is/are activated by TG2 for MMP13 expression, we compared the ability of wild-type and $T g m 2^{-/-}$MDFs to enhance AP-1 and NF- $\mathrm{B}$ dependent transcription in response to poly(I:C) treatment. In MDFs transfected with AP-1 luciferase reporter, there was no difference in AP-1 reporter activity between wild type and $T g m 2^{-/-}$cells, although an increased activity by poly(I:C) treatment was observed in both cells (Figure 5A). In MDFs transfected with 3 kB luciferase reporter, in sharp contrast, poly(I:C) treatment caused an approximately eightfold increase of reporter activity in wild-type cells but not in Tgm2 $2^{-/-}$MDFs, compared with saline-treated cells (Figure 5B). To confirm these results, we compared protein levels of c-jun and p65 in wild-type and Tgm2-/- MDFs after poly(I:C)-treatment. Western blot analysis showed an increased level of c-jun protein in both cells, but there was no difference between wild-type and Tgm2 $2^{-/-}$cells. By contrast, poly(I:C) treatment enhanced the phosphorylation of p65 at Ser 536 in wild-type MDFs, but not in $\mathrm{Tgm}^{-/-}$cells (Figure 5C). When cells were separated into nuclear and cytoplasmic fractions, the level of p65 in the nucleus was significantly increased in wild-type MDFs, but not in $T g m 2^{-/-}$cells, compared with salinetreated MDFs (Figure 5D), indicating that TG2 is responsible for poly(I:C)-induced NF-kB activation leading to MMP13 expression. 
A
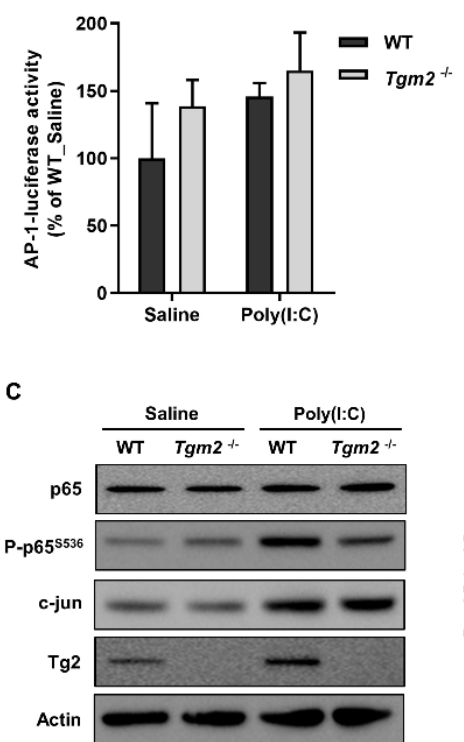

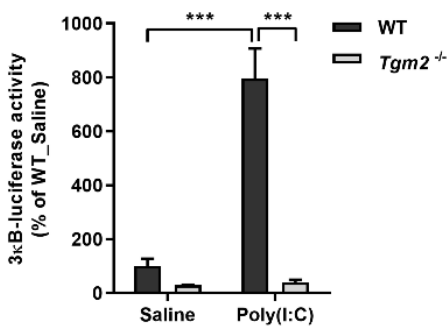

D
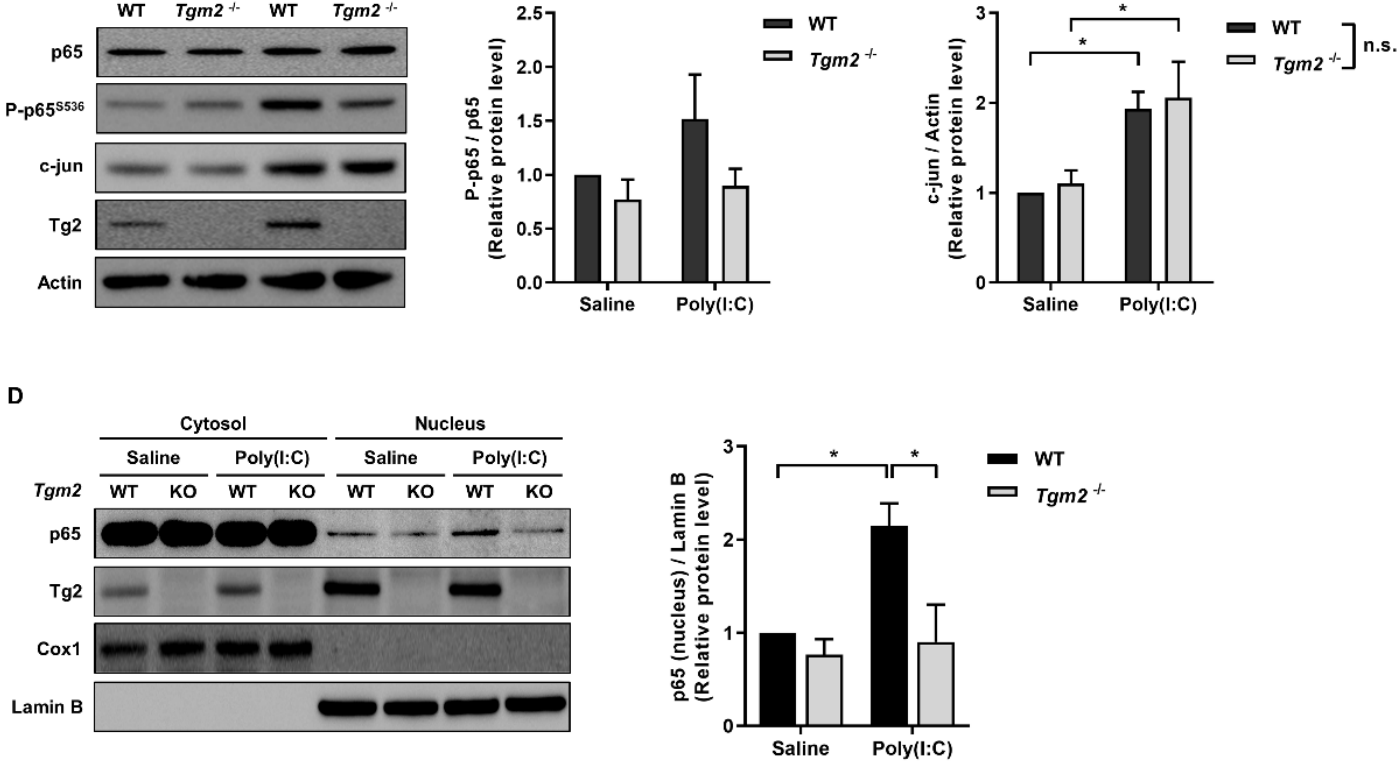

Figure 5. TG2 mediates poly(I:C)-induced NF-kB activation. (A,B) Wild-type and Tgm2 ${ }^{-/-}$MDFs were transfected with expression vector encoding AP-1 (A), or $3 \kappa \mathrm{B}-$ luciferase reporter (B). Luciferase activity was measured after treatment of cells with $20 \mu \mathrm{g} / \mathrm{mL}$ of poly(I:C) for $9 \mathrm{~h}$. $(n=3)$ (C) Wildtype and $\mathrm{Tgm} 2^{-/-}$MDFs were treated with $20 \mu \mathrm{g} / \mathrm{mL}$ of poly(I:C) for $9 \mathrm{~h}$. Total cell extracts were immunoblotted with anti-p65, p-65 $5^{\mathrm{S} 536}$ and c-jun antibodies (left). The ratios of p-p65 5536 to p65 and c-jun to Actin were estimated by densitometric analysis of Western blot (right, $n=7$ ). (D) Lysates prepared from wild-type and Tgm2 ${ }^{-/-}$MDFs treated with $20 \mu \mathrm{g} / \mathrm{mL}$ of poly(I:C) for $6 \mathrm{~h}$ were separated into cytoplasmic and nuclear fractions. The nuclear translocation of p65 was assessed by immunoblotted with anti-p65 antibody (left, a representative image). The ratio of p65 to Lamin B was estimated by densitometric analysis of Western blot (right, $n=3$ ). Cox- 1 and Lamin B were used as an internal control for cytoplasmic and nuclear fraction, respectively. All data are represented as mean \pm SEM. Statistical significance was tested by two-way ANOVA by Turkey's post-test. * $p<0.05$; ***, $p<0.001$; n.s., not significant.

We next corroborated the role of TG2 in vivo, and to this end we used ex vivo skin culture model $[14,20]$. Skin explants were prepared from neonatal mice and cultured with various doses of poly(I:C) for $24 \mathrm{~h}$. Western blot analysis showed a dose-dependent increase of Mmp13 protein (Figure 6A). In skin explants from wild-type mice, poly(I:C) significantly increased the level of Mmp13, whereas in skin explants from Tgm2 ${ }^{-1}-$ mice poly(I:C) had no effect compared with saline-treated skin explants (Figure 6B). Under these conditions, we assessed the level of intracellular TG activity in the skin explants by measuring BP incorporated into cellular protein for $1 \mathrm{~h}$ prior to harvest. In skin explants from wild-type mice, poly(I:C) treatment caused an approximately three-fold increase in TG activity, while poly(I:C) had minimal effect in skin explants from $\mathrm{ggm}^{-/-}$mice (Figure $6 \mathrm{C}$ ). These results further support a critical role of TG2 in the regulation of poly(I:C)-induced MMP expression. 
A
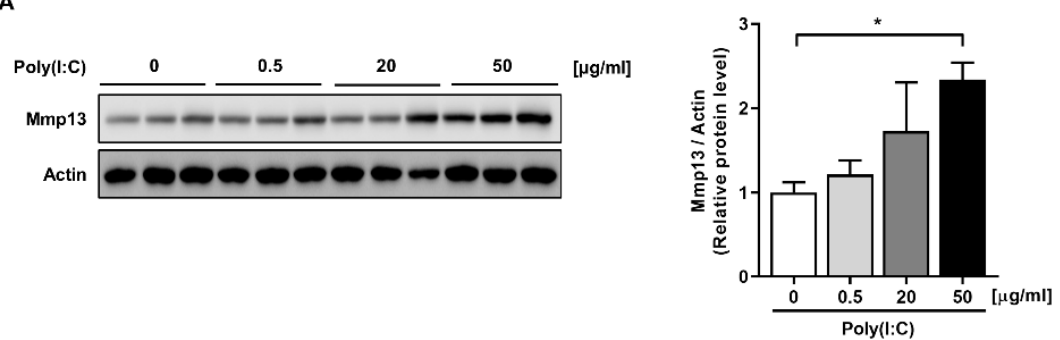

B
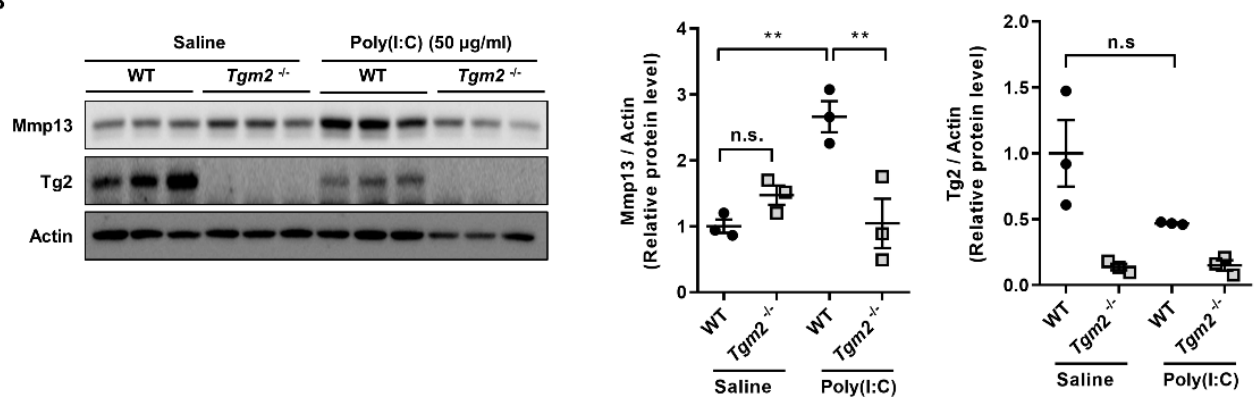

c

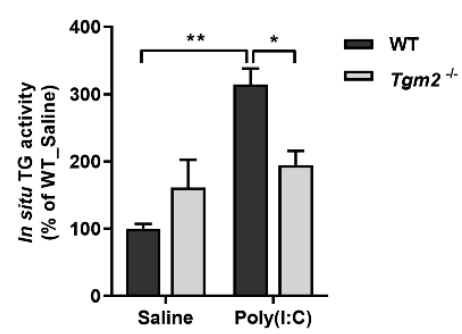

D

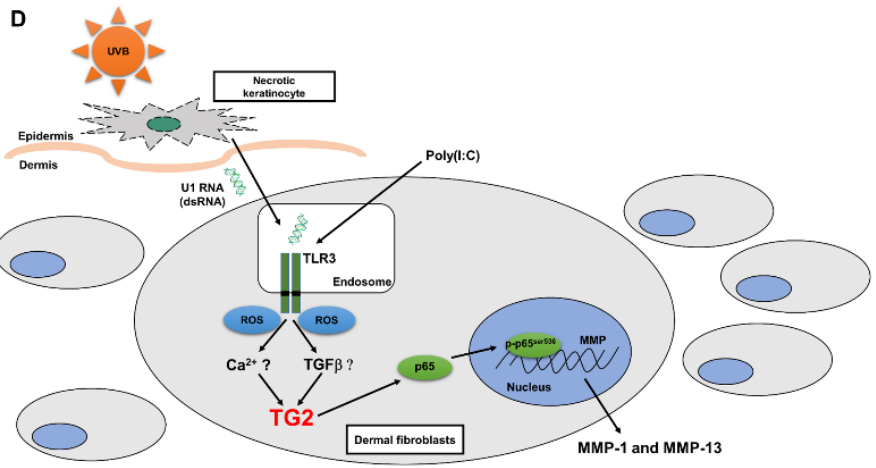

Figure 6. Ex vivo-cultured Tgm2 $2^{-/-}$mouse skin shows reduced Mmp13 expression in response to poly(I:C) treatment. (A,B) Skin explants were prepared from wild-type and $T g m 2^{-/-}$neonatal mice treated with various doses (A) or $50 \mu \mathrm{g} / \mathrm{mL}(\mathbf{B})$ of poly(I:C) for $24 \mathrm{~h}$. Total skin extracts were immunoblotted with anti-Mmp13 antibody (left, $n=3$ ). The ratio of Mmp13 or Tg2 to Actin was estimated by densitometric analysis of Western blot (right). (C) Effect of poly(I:C) treatment $(50 \mu \mathrm{g} / \mathrm{mL}$ for $9 \mathrm{~h})$ on in situ TG activity in wild-type and Tgm $2^{-/-}$mouse skin explants. Intracellular TG activity was assessed by BP incorporation assay. $(n=3)(\mathrm{D})$ A schematic representation of poly(I:C)-induced MMPs expression through TG2 activation. All data are represented as mean \pm SEM. Statistical significance was tested by one-way ANOVA by Dunnett's post-test (A) or two-way ANOVA by Turkey's post-test $(\mathbf{B}, \mathbf{C}) .{ }^{*}, p<0.05 ;{ }^{* *}, p<0.01$; n.s., not significant.

\section{Discussion}

UV irradiation increases MMPs' expression in dermal fibroblasts that leads to fragmentation and loss of collagen fibrils, the most abundant ECM protein in skin dermis, resulting in thin and fragile skin [21-24]. Previous reports showed that dsRNA is generated in the skin following UV-irradiation, and is responsible for enhancing MMPs' expression, thereby inducing alterations of dermal ECM [2,7]. Although the NF- $\mathrm{BB}$ and AP-1 signaling pathways are involved in MMPs' expression, how dsRNA activates these pathways is not fully understood. Previously, we showed that TG2 is activated under various oxidative stress conditions, including UV irradiation, ROS-generating chemotherapeutics and $\mathrm{H}_{2} \mathrm{O}_{2}$ treatment [11-13,25-27]. Moreover, poly(I:C) treatment generates ROS through TLR3 binding in macrophages [17]. In this study, therefore, we tested whether poly(I:C) treatment could activate TG2. Our results showed that poly(I:C) generates ROS by binding to TLR3 and by an unknown mechanism, which activates TG2 in dermal fibroblast. Subsequently, 
TG2 activity enhances translocation of p65 into the nucleus, where it augments transcription of MMPs. These results indicate that TG2 serves as an effector enzyme that links dsRNA and NF- $\kappa B$ activation in dermal fibroblasts, resulting in ECM dysregulation by promoting MMPs' expression.

TLR3, a member of the pattern recognition receptor family, specifically recognizes dsRNA produced in virus-infected cells. In immune cells, dsRNA binding to TLR3 activates IRF3 and NF- $\mathrm{B}$ through MyD88-independent pathway, inducing the expression of type I interferon and proinflammatory cytokines that exert a potent antiviral immunity $[16,28]$. Mechanistically, TLR3 recruits TICAM1 which undergoes oligomerization and in turn recruits TBK1/IKK $\varepsilon$ and RIP1/TAK1, leading to activation of IRF3 and NF- $\mathrm{B}$, respectively [29]. However, the TLR3 signaling pathway in dermal fibroblasts has not been elucidated. The results described here showed that poly(I:C) induces TLR3-dependent ROS production which causes TG2 activation, leading to MMPs' expression through NF- $\mathrm{kB}$ activation. In support of these results, previous reports showed that wild-type mice receiving TG2-deficient bone marrow cells exhibit a similar inflammatory response to bleomycin, a ROS producing chemotherapeutics [30], or imiquimod, a ligand of TLR7, compared with wild-type mice [26,27]. Furthermore, TG2 is dispensable for differentiation of T-cell and macrophage [27]. Thus, our findings provide a new mechanism for dsRNA-induced NF- $\mathrm{B}$ activation in non-immune cells.

UV irradiation induces the formation of DNA lesions, such as pyrimidine dimer, that activates signaling pathways participated in DNA repair and cell cycle control, leading to cell survival or apoptosis [31,32]. Moreover, keratinocytes secrete a variety of bioactive molecules that are upregulated by p53-dependent transcriptional control, and mediate autocrine and paracrine DNA damage responses. For instance, $\alpha-\mathrm{MSH}$, a cleavage product of p53-induced pro-opiomelanocortin, is secreted from UV-exposed keratinocytes, and stimulates melanin synthesis in melanocytes, contributing to protection from UV-induced DNA damage [33]. Similarly, dsRNA derived from double-stranded RNA domains of damaged cellular RNA is secreted from UV-exposed keratinocytes, and in turn induces paracrine production of various cytokines, including TNF- $\alpha$ and IL-6, thereby eliciting acute inflammation of the skin and systemic immune suppression [6]. Our results have shown that dsRNA is one of the molecules responsible for UV-induced upregulation of MMP expression through activation of NF- $\mathrm{B}$ in dermal fibroblasts. Combined with the similar paracrine NF- $\mathrm{kB}$ activation of dsRNA in keratinocytes, our findings suggest that dsRNA released from keratinocytes functions as a signaling molecule for DNA damaging responses in dermal skin.

TGF $\beta$ play a key role in maintaining dermal ECM [34,35]. Binding to its cell surface receptor T $\beta$ RII-T $\beta$ RI transmits signals by phosphorylating Smad2/3 which recruits Smad4. The Smad complex are then translocated into the nucleus, where it enhances the transcription of ECM proteins [36]. Previously, we have reported that TGF $\beta$ signaling activates TG2 in a Smad-dependent manner [37]. In the skin, however, UV-irradiation suppresses TGF $\beta$ signaling by reducing T $\beta$ RII expression [38]. Thus, our results indicate that dsRNA-induced TG2 activation is not dependent on TGF $\beta$ signaling, but on TLR3 signaling. Moreover, our results provide conflicting evidence on the role of TG2 in the regulation of ECM homeostasis. Whereas TGF $\beta$-dependent TG2 activation resulted in lung fibrosis in bleomycin-treated mice [27], the results described here showed that TLR3-dependent TG2 activation causes collagen degradation in dsRNA-treated skin. In addition, TG2 is dispensable in the development of liver cirrhosis in carbon tetrachloride or thioacetamide-treated mice [39]. By sharp contrast, TG2 contributed to renal fibrogenesis in subtotal nephrectomy or a urethral obstruction model through TGF $\beta$ activation $[40,41]$. These findings suggest that the effect of TG2 activation on ECM is likely to depend on activating agent or fibroblast cell type, although the possibility that other factors, such as inflammatory cytokines, may be involved in the TG2-mediated regulation of both collagen and MMP expression in fibroblasts cannot be excluded. Moreover, externalized TG2-mediated crosslinking of 
collagen fibrils may limit MMP-1 or -13 activities, resulting in fragmented and coarsely distributed collagen fibrils, as observed in skin chronically exposed to UV radiation.

In the present study, we have investigated a mechanism explaining how dsRNA secreted from keratinocytes in response to UV-irradiation enhances MMP expression in dermal fibroblasts, providing a new target for preventing UV-induced dermal ECM dysregulation. In this respect, it may be worth testing the effect of agents that exhibit inhibitory activity for intracellular TG2 on photoaging of skin.

\section{Materials and Methods}

\subsection{Cell Culture and Poly (I:C) Treatment}

Human dermal fibroblasts (HDFs) were purchased from Gibco. Primary mouse dermal fibroblasts (MDFs) were prepared from neonatal mice skin as previously described [14]. Cells were cultured in Dulbecco's Modified Essential Medium (DMEM, Welgene, Gyeongsan-si, Korea) supplemented with 10\% fetal bovine serum (FBS) (Hyclone), 100 units $/ \mathrm{mL}$ penicillin and $100 \mu \mathrm{g} / \mathrm{mL}$ streptomycin (PS) (Thermo Fisher Scientific, Waltham, MA, USA). For poly(I:C) (invivogen, San Diego, CA, USA, tlrl-pic-5) treatment, cells were first serum-starved starved for $24 \mathrm{~h}$ in DMEM containing $0.1 \%$ FBS. Then, cells were treated with saline (for vehicle) or indicated concentrations of poly(I:C) for 12 or $24 \mathrm{~h}$. MDFs or HDFs were used under passage 3 or 8 , respectively.

\subsection{Isolation of Mouse Dermal Fibroblasts and Ex Vivo Mouse Skin Culture}

Mouse dermal fibroblasts (MDFs) were prepared from neonatal mice skin as previously described [14]. For ex vivo skin culture, the skin removed from WT or Tgm2 ${ }^{-/-}$neonate mouse was incubated in DMEM containing $0.1 \%$ FBS and 1\% PS for $24 \mathrm{~h}$. Then, the skin was treated with poly(I:C) $(50 \mu \mathrm{g} / \mathrm{mL})$ for next $24 \mathrm{~h}$. All animal experiments were approved by the institutional animal care and use committee (IACUC) of Seoul National University (SNU-160613-4).

\section{3. siRNA Transfection}

For siRNA transfection, GFP (used as control siRNA) and TG2 siRNAs (Santa Cruz Biotechnology, Dallas, TX, USA, sc-45924 and sc-37514) were transfected using RNAiMAX (Invitrogen, Thermo Fisher Scientific, Waltham, MA, USA) according to the manufacturer's instructions. All experimental procedures were carried out $24 \mathrm{~h}$ after transfection.

\subsection{Total RNA Extraction and $q R T-P C R$}

Total RNA was extracted from cells and mouse skin using an RNA-Spin Total RNA extraction kit (iNtRON biotechnology, Seongnam-si, Korea). Extracted RNA was then converted to cDNA using oligo-dT primers and Superscript II reverse transcriptase (Invitrogen, Thermofisher, Waltham, MA, USA). qRT-PCR was performed with a CFX96 real-time system (Biorad, Hercules, CA, USA) using SYBR qPCR master mix (Kapa Biosystems, Wilmington, MA, USA). The sequences of forward and reverse primers are designed as the following; mouse $36 b 4$ forward, $5^{\prime}$-GAGGCCACACTGAACAT- $3^{\prime}$, reverse, $5^{\prime}$ ATGCTGCCGTTGTCAAACAC-3'; Mmp13 forward, 5' -AGGAAGACCTTGTGTTTGCAGA GC-3' ${ }^{\prime}$, reverse, 5' -TTCAGGATTCCCGCAAGAGTCG-3'; human 36B4 forward, 5' -GCCAAT AGACAGGAGCGCTATC-3' ${ }^{\prime}$, reverse, 5' -AAAGACGATGTCACTTCCACGAG-3'; MMP1 forward, 5'-GGTGTCTCACAGCTTCCCAG-3' , reverse, 5' -CCGCTTTTCAACTTCCCTCC$3^{\prime}$. Relative mRNA expression was calculated by $2^{-\Delta \Delta C t}$ method. Gene expression was normalized to mouse 3664 or human $36 B 4$.

\subsection{Western Blot Analysis}

Cell lysis, protein sampling and western blot analysis were performed as described previously [42]. Mouse skin samples were homogenized in RIPA buffer (50 mM Tris-Cl, pH 7.4, $150 \mathrm{mM} \mathrm{NaCl}, 1 \% \mathrm{NP}-40,1 \%$ Sodium deoxycholate and 0.1\% SDS) by Ultra-Turrax Dispenser (IKA, Staufen, Germany). The following antibodies were used in this study: 
anti-MMP13 (Neomarkers, Santa Cruz Biotechnology, Dallas, TX, USA, MS-827-P1) antiMMP1 (Santa Cruz Biotechnology, Dallas, TX, USA, sc-8834) anti-b actin, anti-p65 (Cell signaling Technology, Danvers, MA, USA, \#8242), anti-COX1 (Santa Cruz Biotechnology, Dallas, TX, USA, sc-1752), anti-Lamin B (Santa Cruz Biotechnology, Dallas, TX, USA, sc-6216). Monoclonal antibody against TG2 was prepared as described previously [10]. Immunoblots were quantitated by Image J software (http:/ / rsb.info.nih.gov/ij/, accessed on 1 March 2016).

\subsection{In Situ Transglutaminase Assay}

In situ transglutaminase (TG) assay was measured as described previously [43]. Following $12 \mathrm{~h}$ poly(I:C) treatment, cells were incubated with $1 \mathrm{mM}$ EZ-link Pentylamine-Biotin (BP) (Thermo Fisher Scientific, Waltham, MA, USA) as a TG substrate in serum-free DMEM for $1 \mathrm{~h}$. These BP-incorporated cells were reacted with Alexa green-conjugated streptavidin (Thermo Fisher Scientific, Waltham, MA, USA) and visualized using FV-1000 confocal laser-scanning microscope (Olympus, Tokyo, Japan).

\subsection{Cell In Situ Zymography}

To measure the MMP activity in cells, Cell in situ zymography was performed and quantified as previously described [14,44]. Briefly, cells were incubated on the sterile cover slip and then treated with $20 \mu \mathrm{g} / \mathrm{mL}$ poly(I:C) for $12 \mathrm{~h}$. The cells were fixed with methanol for $15 \mathrm{~min}$ at $-20^{\circ} \mathrm{C}$ and then, incubated with $10 \mu \mathrm{g} / \mathrm{mL}$ highly quenched FITC-labeled $\mathrm{DQ}^{\mathrm{TM}}$-collagen type-I (Molecular Probes, Thermo Fisher Scientific, Waltham, MA, USA) at $37^{\circ} \mathrm{C}$ for $1 \mathrm{~h}$. After incubation and wash six times with $1 \mathrm{X}$ PBS, the coverslips were mounted and observed using FV-1000 confocal laser-scanning microscope (Olympus, Tokyo, Japan). Corrected Total Cell Fluorescence (CTCF) were calculated by Image J software (http://rsb.info.nih.gov/ij/, accessed on 1 March 2016).

$\mathrm{CTCF}=$ Integrated density of selected cell $-($ Area of selected cell $\times$ Mean fluorescence of background $)$.

\subsection{Measurement of Intracellular ROS}

Intracellular ROS levels were measured by the fluorescence intensity of the $2^{\prime} 7^{\prime}$ dichlorofluroescein diacetate $\left(\mathrm{H}_{2}\right.$ DCF-DA) (Thermo Fisher Scientific, Waltham, MA, USA). $\mathrm{H}_{2}$ DCF-DA was reconstituted in DMSO to make a concentrated stock solution. After $15 \mathrm{~min}$ of poly(I:C) treatment, cells pre-treated with or without $20 \mu \mathrm{g} / \mathrm{mL}$ poly(I:C) were incubated in DMEM containing $0.1 \%$ FBS for the indicated time. Cells were then treated with $10 \mu \mathrm{M}$ $\mathrm{H}_{2}$ DCF-DA and incubated at $37^{\circ} \mathrm{C}$ for $15 \mathrm{~min}$ prior to harvest. After poly(I:C) treatment for less than $15 \mathrm{~min}$, cells were pre-treated with $10 \mu \mathrm{M} \mathrm{H}_{2}$ DCF-DA and then treated with $10 \mu \mathrm{M}$ $\mathrm{H}_{2}$ DCF-DA and $20 \mu \mathrm{g} / \mathrm{mL}$ poly(I:C) (or saline) for the indicated time. Cells were washed twice using cold PBS and collected in 2\% FBS-PBS. To measure fluorescence intensity, flow cytometry was performed on BD FACS Calibur (BD Biosciences, Franklin Lakes, NJ, USA) and all data were analyzed using Flowjo 7.6 software (BD Biosciences, Franklin Lakes, NJ, USA).

\subsection{Luciferase Reporter Assay}

For AP-1-luciferase and 3kB-luciferase assay, cells were transfected with 3xAP1pGL3 vector or 3kB-luciferase construct using Lipofectamine 3000 (Invitrogen, Thermofisher, Waltham, MA, USA). 3xAP1pGL3 (3xAP-1 in pGL3-basic) was a gift from Alexander Dent (Addgene plasmid \# 40342; http: / / n2t.net/addgene:40342 (accessed on 23 January 2022); RRID:Addgene_40342) [45]. pRL-TK, encoding Renilla luciferase, was co-transfected to normalize luciferase activity. After $6 \mathrm{~h}$ transfection, cells were incubated in DMEM supplemented with $0.1 \%$ FBS and poly(I:C) $(20 \mu \mathrm{g} / \mathrm{mL})$ for $9 \mathrm{~h}$. Luciferase activity was measured using the Dual-Luciferase Reporter Assay System (Promega, Madison, WI, USA) following the manufacturer's instructions. 


\subsection{Statistical Analysis}

GraphPad Prism 5.0 statistical software (GraphPad Software, San Diego, CA, USA) was used for statistical evaluations. One- or Two-way ANOVA was conducted for evaluation. The statistical details can be found in the figure legends. Significance levels were as follows: ${ }^{*}, p<0.05 ;{ }^{* *}, p<0.01 ;{ }^{* * *}, p<0.001$; and n.s., not significant.

Author Contributions: A.-Y.H., S.-J.L., K.B.L. and J.-W.S. performed the experiments. A.-Y.H., S.-J.L., K.B.L., J.-W.S. and E.M.J. analyzed the experimental data. A.-Y.H., K.B.L. and I.-G.K. wrote the manuscript. A.-Y.H., S.-J.L., K.B.L. and I.-G.K. designed and supervised the study. All authors have read and agreed to the published version of the manuscript.

Funding: This research received no external funding.

Institutional Review Board Statement: Not applicable.

Informed Consent Statement: Not applicable.

Data Availability Statement: The data presented in this study are available on request from the corresponding author.

Acknowledgments: This work was supported by the National Research Foundation of Korea through the Basic Science Research Program (NRF-2017M3A9B4061890, and NRF-2018R1A2B3008541); the Korea Healthcare Technology R\&D Project, Ministry of Health and Welfare, Republic of Korea (HI18C2396); the Korean Fund for Regenerative Medicine(KFRM) grant funded by the Korea government(the Ministry of Science and ICT, the Ministry of Health \& Welfare) (HH21C0004); and the Brain Korea 21 PLUS program of the Korean Ministry of Education, Science and Technology. Tlr $3^{-/-}$ mouse were kind gift from Jin Ho Chung, Seoul National University College of Medicine.

Conflicts of Interest: The authors have no conflict of interest to declare.

\section{References}

1. Fisher, G.J.; Kang, S.; Varani, J.; Bata-Csorgo, Z.; Wan, Y.; Datta, S.; Voorhees, J.J. Mechanisms of photoaging and chronological skin aging. Arch. Dermatol. 2002, 138, 1462-1470. [CrossRef]

2. Pittayapruek, P.; Meephansan, J.; Prapapan, O.; Komine, M.; Ohtsuki, M. Role of Matrix Metalloproteinases in Photoaging and Photocarcinogenesis. Int. J. Mol. Sci. 2016, 17, 868. [CrossRef] [PubMed]

3. Rittie, L.; Fisher, G.J. Natural and sun-induced aging of human skin. Cold Spring Harb. Perspect. Med. 2015, 5, a015370. [CrossRef]

4. Hur, S. Double-Stranded RNA Sensors and Modulators in Innate Immunity. Annu. Rev. Immunol. 2019, 37, 349-375. [CrossRef] [PubMed]

5. Chattopadhyay, S.; Sen, G.C. dsRNA-activation of TLR3 and RLR signaling: Gene induction-dependent and independent effects. J. Interferon Cytokine Res. 2014, 34, 427-436. [CrossRef]

6. Bernard, J.J.; Cowing-Zitron, C.; Nakatsuji, T.; Muehleisen, B.; Muto, J.; Borkowski, A.W.; Martinez, L.; Greidinger, E.L.; Yu, B.D.; Gallo, R.L. Ultraviolet radiation damages self noncoding RNA and is detected by TLR3. Nat. Med. 2012, 18, 1286-1290. [CrossRef]

7. Yao, C.; Lee, D.H.; Oh, J.H.; Kim, M.K.; Kim, K.H.; Park, C.H.; Chung, J.H. Poly(I:C) induces expressions of MMP-1, -2, and -3 through various signaling pathways including IRF3 in human skin fibroblasts. J. Dermatol. Sci. 2015, 80, 54-60. [CrossRef] [PubMed]

8. Iismaa, S.E.; Mearns, B.M.; Lorand, L.; Graham, R.M. Transglutaminases and disease: Lessons from genetically engineered mouse models and inherited disorders. Physiol. Rev. 2009, 89, 991-1023. [CrossRef] [PubMed]

9. Kim, H.J.; Lee, J.H.; Lee, K.B.; Shin, J.W.; Kwon, M.A.; Lee, S.; Jeong, E.M.; Cho, S.Y.; Kim, I.G. Transglutaminase 2 crosslinks the glutathione S-transferase tag, impeding protein-protein interactions of the fused protein. Exp. Mol. Med. 2021, 53, 115-124. [CrossRef]

10. Jeon, J.H.; Choi, K.H.; Cho, S.Y.; Kim, C.W.; Shin, D.M.; Kwon, J.C.; Song, K.Y.; Park, S.C.; Kim, I.G. Transglutaminase 2 inhibits $\mathrm{Rb}$ binding of human papillomavirus E7 by incorporating polyamine. EMBO J. 2003, 22, 5273-5282. [CrossRef]

11. Shin, D.M.; Jeon, J.H.; Kim, C.W.; Cho, S.Y.; Kwon, J.C.; Lee, H.J.; Choi, K.H.; Park, S.C.; Kim, I.G. Cell type-specific activation of intracellular transglutaminase 2 by oxidative stress or ultraviolet irradiation: Implications of transglutaminase 2 in age-related cataractogenesis. J. Biol. Chem. 2004, 279, 15032-15039. [CrossRef] [PubMed]

12. Cho, S.Y.; Jeong, E.M.; Lee, J.H.; Kim, H.J.; Lim, J.; Kim, C.W.; Shin, D.M.; Jeon, J.H.; Choi, K.; Kim, I.G. Doxorubicin induces the persistent activation of intracellular transglutaminase 2 that protects from cell death. Mol. Cells 2012, 33, 235-241. [CrossRef] [PubMed]

13. Lee, S.J.; Lee, K.B.; Son, Y.H.; Shin, J.; Lee, J.H.; Kim, H.J.; Hong, A.Y.; Bae, H.W.; Kwon, M.A.; Lee, W.J.; et al. Transglutaminase 2 mediates UV-induced skin inflammation by enhancing inflammatory cytokine production. Cell Death Dis. 2017, 8, e3148. [CrossRef] 
14. Lee, S.J.; Lee, K.B.; Hong, A.Y.; Son, Y.H.; Lee, D.H.; Jeong, E.M.; Kim, I.G. Transglutaminase 2 mediates UVB-induced matrix metalloproteinase-1 expression by inhibiting nuclear p65 degradation in dermal fibroblasts. Exp. Dermatol. 2021, Early view. [CrossRef] [PubMed]

15. Jedeszko, C.; Sameni, M.; Olive, M.B.; Moin, K.; Sloane, B.F. Visualizing protease activity in living cells: From two dimensions to four dimensions. Curr. Protoc. Cell Biol. 2008, 39, 4-20. [CrossRef] [PubMed]

16. Zhou, Y.; Wang, X.; Liu, M.; Hu, Q.; Song, L.; Ye, L.; Zhou, D.; Ho, W. A critical function of toll-like receptor-3 in the induction of anti-human immunodeficiency virus activities in macrophages. Immunology 2010, 131, 40-49. [CrossRef] [PubMed]

17. Yang, C.S.; Kim, J.J.; Lee, S.J.; Hwang, J.H.; Lee, C.H.; Lee, M.S.; Jo, E.K. TLR3-triggered reactive oxygen species contribute to inflammatory responses by activating signal transducer and activator of transcription-1. J. Immunol. 2013, 190, 6368-6377. [CrossRef]

18. Liacini, A.; Sylvester, J.; Li, W.Q.; Huang, W.S.; Dehnade, F.; Ahmad, M.; Zafarullah, M. Induction of matrix metalloproteinase-13 gene expression by TNF-alpha is mediated by MAP kinases, AP-1, and NF-kappa B transcription factors in articular chondrocytes. Exp. Cell Res. 2003, 288, 208-217. [CrossRef]

19. Zhang, S.Y.; Herman, M.; Ciancanelli, M.J.; Perez de Diego, R.; Sancho-Shimizu, V.; Abel, L.; Casanova, J.L. TLR3 immunity to infection in mice and humans. Curr. Opin. Immunol. 2013, 25, 19-33. [CrossRef]

20. Lichti, U.; Anders, J.; Yuspa, S.H. Isolation and short-term culture of primary keratinocytes, hair follicle populations and dermal cells from newborn mice and keratinocytes from adult mice for in vitro analysis and for grafting to immunodeficient mice. Nat. Protoc. 2008, 3, 799-810. [CrossRef]

21. Costa, A.; Eberlin, S.; Clerici, S.P.; Abdalla, B.M. In vitro effects of infrared A radiation on the synthesis of MMP-1, catalase, superoxide dismutase and GADD45 alpha protein. Inflamm. Allergy Drug Targets 2015, 14, 53-59. [CrossRef] [PubMed]

22. Quan, T.; Little, E.; Quan, H.; Qin, Z.; Voorhees, J.J.; Fisher, G.J. Elevated matrix metalloproteinases and collagen fragmentation in photodamaged human skin: Impact of altered extracellular matrix microenvironment on dermal fibroblast function. J. Investig. Dermatol. 2013, 133, 1362-1366. [CrossRef] [PubMed]

23. Park, C.H.; Lee, M.J.; Ahn, J.; Kim, S.; Kim, H.H.; Kim, K.H.; Eun, H.C.; Chung, J.H. Heat shock-induced matrix metalloproteinase (MMP)-1 and MMP-3 are mediated through ERK and JNK activation and via an autocrine interleukin-6 loop. J. Investig. Dermatol. 2004, 123, 1012-1019. [CrossRef] [PubMed]

24. Kim, H.H.; Lee, M.J.; Lee, S.R.; Kim, K.H.; Cho, K.H.; Eun, H.C.; Chung, J.H. Augmentation of UV-induced skin wrinkling by infrared irradiation in hairless mice. Mech. Ageing Dev. 2005, 126, 1170-1177. [CrossRef]

25. Jeong, E.M.; Kim, C.W.; Cho, S.Y.; Jang, G.Y.; Shin, D.M.; Jeon, J.H.; Kim, I.G. Degradation of transglutaminase 2 by calciummediated ubiquitination responding to high oxidative stress. FEBS Lett. 2009, 583, 648-654. [CrossRef]

26. Shin, J.W.; Kwon, M.A.; Hwang, J.; Lee, S.J.; Lee, J.H.; Kim, H.J.; Lee, K.B.; Lee, S.J.; Jeong, E.M.; Chung, J.H.; et al. Keratinocyte transglutaminase 2 promotes CCR6(+) gammadeltaT-cell recruitment by upregulating CCL20 in psoriatic inflammation. Cell Death Dis. 2020, 11, 301. [CrossRef]

27. Oh, K.; Park, H.B.; Byoun, O.J.; Shin, D.M.; Jeong, E.M.; Kim, Y.W.; Kim, Y.S.; Melino, G.; Kim, I.G.; Lee, D.S. Epithelial transglutaminase 2 is needed for $\mathrm{T}$ cell interleukin-17 production and subsequent pulmonary inflammation and fibrosis in bleomycin-treated mice. J. Exp. Med. 2011, 208, 1707-1719. [CrossRef]

28. Kawai, T.; Akira, S. Signaling to NF-kappaB by Toll-like receptors. Trends Mol. Med. 2007, 13, 460-469. [CrossRef]

29. Chau, T.L.; Gioia, R.; Gatot, J.S.; Patrascu, F.; Carpentier, I.; Chapelle, J.P.; O’Neill, L.; Beyaert, R.; Piette, J.; Chariot, A. Are the IKKs and IKK-related kinases TBK1 and IKK-epsilon similarly activated? Trends Biochem. Sci. 2008, 33, 171-180. [CrossRef]

30. Wallach-Dayan, S.B.; Izbicki, G.; Cohen, P.Y.; Gerstl-Golan, R.; Fine, A.; Breuer, R. Bleomycin initiates apoptosis of lung epithelial cells by ROS but not by Fas/FasL pathway. Am. J. Physiol. Lung Cell Mol. Physiol. 2006, 290, L790-L796. [CrossRef]

31. Lee, C.H.; Wu, S.B.; Hong, C.H.; Yu, H.S.; Wei, Y.H. Molecular Mechanisms of UV-Induced Apoptosis and Its Effects on Skin Residential Cells: The Implication in UV-Based Phototherapy. Int. J. Mol. Sci. 2013, 14, 6414-6435. [CrossRef] [PubMed]

32. Svobodova, A.; Walterova, D.; Vostalova, J. Ultraviolet light induced alteration to the skin. Biomed. Pap. Med. Fac. Univ. Palacky Olomouc 2006, 150, 25-38. [CrossRef] [PubMed]

33. Chen, H.X.; Weng, Q.Y.; Fisher, D.E. UV Signaling Pathways within the Skin. J. Investig. Dermatol. 2014, 134, 2080-2085. [CrossRef] [PubMed]

34. Mauviel, A. Transforming growth factor-beta signaling in skin: Stromal to epithelial cross-talk. J. Investig. Dermatol. 2009, 129, 7-9. [CrossRef]

35. Horiguchi, M.; Ota, M.; Rifkin, D.B. Matrix control of transforming growth factor-beta function. J. Biochem. 2012, 152, 321-329. [CrossRef]

36. Verrecchia, F.; Chu, M.L.; Mauviel, A. Identification of novel TGF-beta/Smad gene targets in dermal fibroblasts using a combined cDNA microarray/promoter transactivation approach. J. Biol. Chem. 2001, 276, 17058-17062. [CrossRef]

37. Shin, D.M.; Jeon, J.H.; Kim, C.W.; Cho, S.Y.; Lee, H.J.; Jang, G.Y.; Jeong, E.M.; Lee, D.S.; Kang, J.H.; Melino, G.; et al. TGF beta mediates activation of transglutaminase 2 in response to oxidative stress that leads to protein aggregation. FASEB J. 2008, 22, 2498-2507. [CrossRef]

38. Quan, T.H.; He, T.Y.; Kang, S.; Voorhees, J.J.; Fisher, G.J. Solar ultraviolet irradiation reduces collagen in photoaged human skin by blocking transforming growth factor-beta type II receptor/Smad signaling. Am. J. Pathol. 2004, 165, 741-751. [CrossRef] 
39. Popov, Y.; Sverdlov, D.Y.; Sharma, A.K.; Bhaskar, K.R.; Li, S.Y.; Freitag, T.L.; Lee, J.; Dieterich, W.; Melino, G.; Schuppan, D. Tissue Transglutaminase Does Not Affect Fibrotic Matrix Stability or Regression of Liver Fibrosis in Mice. Gastroenterology 2011, 140, 1642-1652. [CrossRef]

40. Shweke, N.; Boulos, N.; Jouanneau, C.; Vandermeersch, S.; Melino, G.; Dussaule, J.C.; Chatziantoniou, C.; Ronco, P.; Boffa, J.J. Tissue transglutaminase contributes to interstitial renal fibrosis by favoring accumulation of fibrillar collagen through TGF-beta activation and cell infiltration. Am. J. Pathol. 2008, 173, 631-642. [CrossRef]

41. Johnson, T.S.; Griffin, M.; Thomas, G.L.; Skill, J.; Cox, A.; Yang, B.; Nicholas, B.; Birckbichler, P.J.; MuchanetaKubara, C.; El Nahas, A.M. The role of transglutaminase in the rat subtotal nephrectomy model of renal fibrosis. J. Clin. Investig. 1997, 99, 2950-2960. [CrossRef] [PubMed]

42. Lee, S.J.; Son, Y.H.; Lee, K.B.; Lee, J.H.; Kim, H.J.; Jeong, E.M.; Park, S.C.; Kim, I.G. 4-n-butylresorcinol enhances proteolytic degradation of tyrosinase in B16F10 melanoma cells. Int. J. Cosmet. Sci. 2017, 39, 248-255. [CrossRef] [PubMed]

43. Jang, G.Y.; Jeon, J.H.; Cho, S.Y.; Shin, D.M.; Kim, C.W.; Jeong, E.M.; Bae, H.C.; Kim, T.W.; Lee, S.H.; Choi, Y.; et al. Transglutaminase 2 suppresses apoptosis by modulating caspase 3 and NF-kappaB activity in hypoxic tumor cells. Oncogene 2010, $29,356-367$. [CrossRef]

44. Chhabra, A.; Jaiswal, A.; Malhotra, U.; Kohli, S.; Rani, V. Cell in situ zymography: An in vitro cytotechnology for localization of enzyme activity in cell culture. In Vitro Cell. Dev. Biol. Anim. 2012, 48, 463-468. [CrossRef] [PubMed]

45. Vasanwala, F.H.; Kusam, S.; Toney, L.M.; Dent, A.L. Repression of AP-1 function: A mechanism for the regulation of Blimp1 expression and B lymphocyte differentiation by the B cell lymphoma-6 protooncogene. J. Immunol. 2002, 169, 1922-1929. [CrossRef] 